\title{
EXCITEMENT OF HYDRAULICS AND PNEUMATICS IN UNIVERSITY BY COOPERATION WITH INDUSTRY
}

KEN ICHIRYU TOKYO UNIVERSITY Of TECHNOLOGY, ENGINEERING DEPARTMENT

\section{INTRODUCTION}

At present, fluid power industry is faced with hard struggle between electric drive . Fluid power is essential for sound advancement of mechanical industry. Importance of education of fluid power is beyond dispute. Fluid power engineering is misunderstood not attractive for young students. But, this is not true from my experience. Fluid power becomes splendid engineering for them, if properly educated. One method is practical education by cooperation with industry .

In the following, our experience will be shown

\section{CONCEPT OF "FUTURE MACHINE " LABORATORY}

Fluid power is considered better to relate more wide concept to catch young student heart .

We think fluid power engineering and fluid power control are key factors for 21 century machine, that is for "FUTURE MACHINE ", too .

" FUTURE MACHINE" is attractive name containing more general concept than fluid power, therefore, my laboratory is named as " FUTURE MACHINE " laboratory.

What is " FUTURE MACHINE " laboratory which we imagine ?

(a)First, " FUTURE MACHINE " laboratory is to make new and attractive machine, or innovative machine. Examples are such as hybrid car PRIUS, ASUKA STOL aeroplane, parallel link machine tool or CPS car which JHPS is jointly developing, just now.

(b) Second, FUTURE MACHINE laboratory is to improve machine performance until highest level. Typical examples are motor bicycle where japan has $90 \%$ share .

For the development of "FUTURE MACHINE " laboratory, we have catch phrase "CHALLENGE VIV ".

First $\mathrm{V}$ is " VIRTUAL REALITY " machine, actually parallel link motion base.

Secod I means "INTELLIGENT MACHINE " based on fluid power

Last $\mathrm{V}$ is " ADVANCED VEHICLE " including construction vehicle and personal CPS car.

Every themes are selected for young students to stimulate, from standpoint of being interesting , and practical for both student and industry .

Here, key factor is excitement caused by cooperative work with compani

\section{CONSTITUTION OF " FUTURE MACHINE " LABORATORY}

We organized laboratory under the name of "FUTURE MACHINE " laboratory.

Distribution of members is shown in Fig. 1 .Our laboratory started in 16 numbers in ' 97 . Last year member increased 22 and this year, member is scheduled to increase 25.

In the following, subject and member distribution are shown for each group. Number of 
member is shown inside parenthes.

(A) First group of VIRTUAL REALITY

(motion control of parallel link) in '97 is

6 persons; motion dynamics ( 2 ), application

of motion control for drawing (2), application

of motion control for vibration (2).

Next year, this number increased up to 8 persons, namely, motion dynamics (2), personal freight simulator using motion base (3), machining by motion base (2), vibration study (1).

This year, this group will expand to 10 persons includig 2 master students.

(B) Second group of INTELLIGENT MACHINE in ' 97 is 6 persons; thermodynamic measurement of hydraulic machine (2), Electrohydraulic control of press (2), mechanical vibrator (2)

Next year, this group was also increased 8 students. That is, press control and mechanical vibrator are same numbers. Thermodynamic measurement section decreased to (1) person . Newly appeared subjects are pneumatic control (1), and hydraulic clamping(2) students .

This year, this group members will be decreased 7 persons.

(C) Third group of VEHICLE in '97 started in only (3) students with excavator's trajectory control subject.

Last year, this member increased (6) students by new theme of road repairing machine using endmill cutter. This year, vehicle team will sbsorb more student interest up to (8), including (2) master students .

In our department, choice of diploma subject or master subject is selected by student will, so that, above explained tendancy shows our department student wish .

" FUTURE MACHINE " laboratory, in other word, " FLUID POWER "laboratory attracts many students .Because, to move machine via HYDRAULICS or PNEUMATICS is very interesting and exciting for them .

Some one says FLUID POWER is not welcomed to young. You can understand this is not true . If properly motivated, young people understand FLUID POWER and FLUID ENGINEERING .

\section{EFFECT OF COOPERATION WITH INDUSTRY}

Our laboratory started in april '97 by supports of many companies. Until now, we are strongly promoting cooperative study with indusry as " FUTURE MACHINE " development via FLUID POWER. as our guide way .

Through this procedure, we deeply impressed how important and effective to give students a new field, that is, innovative manufacturing field through cooperative study and development with industry.

On the other hand, to apply innovative power and to use fresh idea of young students, may be 
considered spring of activity for each company . But, Level of diploma or master students is limited, generally speaking, merit for large company having own laboratory, is not high, except for special case. In this case, rather large company becomes teacher for us. This teacher gives very effective and powerful influence on our students, because he is an active expert on that special field just now. To return revenue in this case from our side is difficult. Only thing we can do is to encourage students for future success .

Frankly speaking, we could share equal benefit of cooperation with medium and small companies

There many merits of cooperation ;

(A) Teaching of technical practices in actual factory ; Practices of manufacturing is better teachable by company. For example, drawing is this example. Teaching of engineering drawing by staffs of university is not best for students. Because, cost of product, material selection and tolerance of machining or assembling are closely related to company's experiences. General explanation is not serious.

(B) Technical guidance; Giving professional knowledge to students. Engineering knowledge is only acceptable by accurate real thing. Innovative manufacturing technology also will be absorbed through eager explanation from engineers .

We could not give engineering excitement without personal communication .

(C) Financial support; There are many ways of supports from company . For us ,these are vitally important .

But, as economical situation is not good at present, supports from company is becoming difficult .

As previously mentioned, mutual merit of cooperation is different for company size, fundamental of these activities is mutual merit. Anyway, we must improve ourself, at first, to give balance for industry.

Fundamental is activation of students, because only one resources of university is students . Students is kernel of research and development.

Present students are roughly divided in three groups as follows; $1 / 3 ;$ lover of manufacturing machine such as bike, $1 / 3$; lover of personal computer, grown-up of game boy, last $1 / 3$; intermediate group without speciality. Students of $2 / 3$ with speciality are easy to activate .

Residual $1 / 3$ students are difficult to activate, at first . But, impact of cooperative work is very strong. Those intermediate group, so called inactive students, becomes active at last .

Cooperation with industry gives strong impact for every students .

\section{EXAMPLES OF COOPERATIVE STUDY}

We are supported from 25 companies, at present . Now, let us explain some examples of joint study with companies

(A) "VIRTUAL REALITY" (motion control of parallel link ) group

We have three hydraulic driven small motion bases, one construction machine oriented and one pneumatically driven base, total, 5 motion bases. We are doing versatile reserches of this 
motion base control. Because, this study includes many aspects of mechatronics, students seem exciting and challenging

First study is concerning motion analysis of parallel link. Inverse kinematics is easy to implement for motion base, but direct kinematics is said difficult for diploma subject . But, one of my students completely solved this problem and is trying to apply dynamic control .

That is , study is to drive motion base by inverse kinematics and to make feedback using direct kinematics. Developed softwares are visual display of cylinder motion and motion base itself (Fig.2:) . We are aiming to apply these sotwares for motion base design tool .

Another study is concerning personal freight simulator using small motion base .As simulator software, we are using X-plane which gives pitch, roll etc. These data is diretly converted to motion base movement . Operator sits on the seat mounted on motion base. Joystick and

liquid display for vision are fixed to seat . We are endevouring to realize this personal freight simulator. Last study is concerning machining by motion base system. Now, machine tool manufacturer is attempting to make large scale parallel link machine . But, our intention is different from this .We are making personal scaled engrave machine by applying 6 axis flexible mechanism .

Every themes are not only attractive for students but also practically interesting for industry.

\section{(B) " INTELLIGENT MACHINE "}
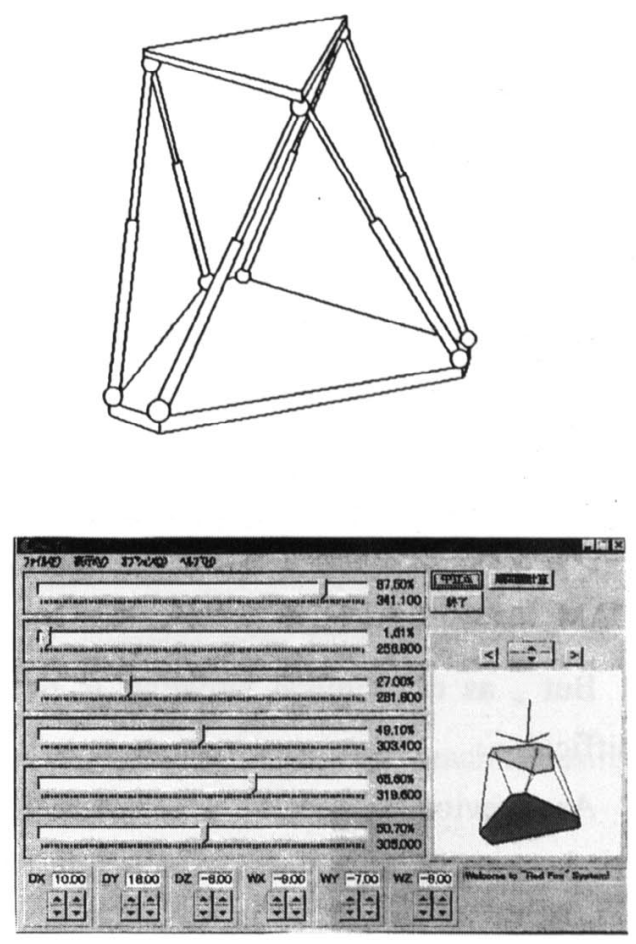

Fig. 2

As previously explained, we are doing many kind of studies in this area. Here, let us briefly explain them . (a) themodynamic measurement of pump efficiency; we applied original plastic hermetic sealed thermo-couple to the estimation of pump efficiency. This thermodynamic efficiency agreed well with mechanical measument in adiabatically sealed condition. This result is quite interesting for condition monitoring .

(b) mechanical vibrator; at first year, this device, self-excited vibrator was confirmed effective for earth stamping for construction machinery ( Fig.3 ) . Now, we are continuing this study . One example is dynamic measurement of each part for performance prediction .

(c) electro-hydraulic control of press; By the support of industy, we are doing advanced control of press .

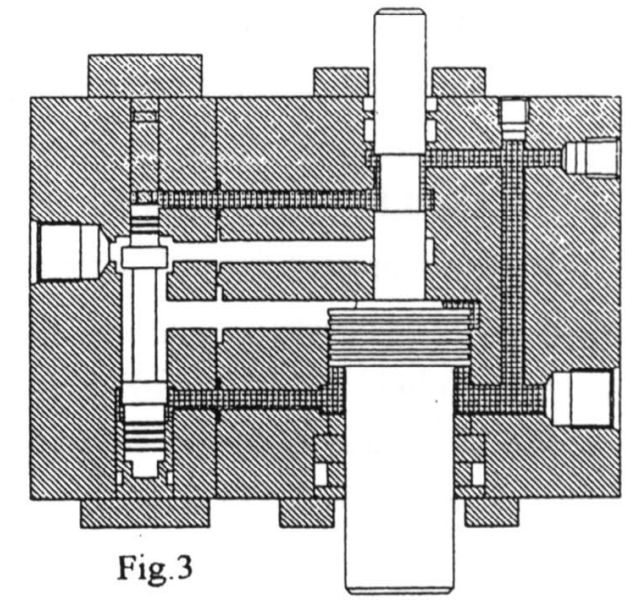


In this study, we are trying digital control by personal computer .

As explained here, every themes are related dynamic motion control or measurement. Every students are attracted by the dynamics of fluid power

(C) " VEHICLE "

This subject is quite attractive for young students. Now, we are building original road repairing machine with end mill cutter as one example of " FUTURE MACHINE " (Fig.4.3). This machine as shown in figure, composed of super structure including engine and operator console, undercarriage with steering apparatus, 4 independent crawlers. In the central part of the machine, there is motion base controlled end mill cutter .

Everywhere of this machine is designed by students under guidance and support of many companies. Assembly or fabrication of the machine, are also made by students .

They are manufacturing innovative vehicle, excitingly. Everything under their control is considered one more factor of their excitement .
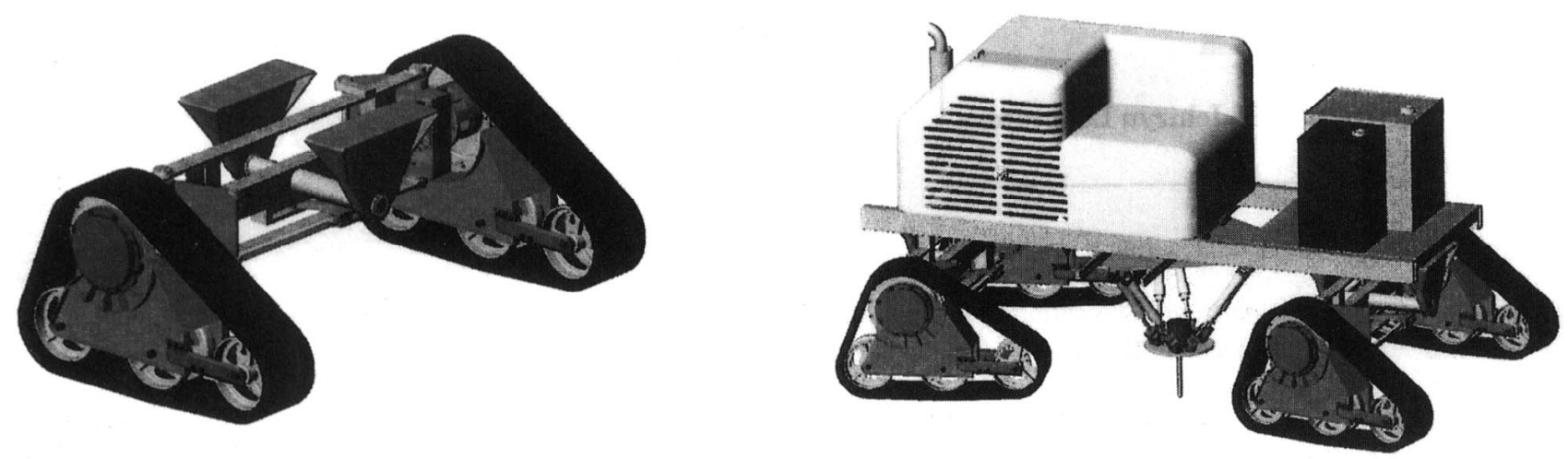

Fig.4

\section{CONCLUSION}

By the examples, we demonstrated how fluid power is exciting for young students. But, we must improve teaching method as to catch their hearts firmly. For this purpose, we proposed wider concept of " FUTURE MACHINE " .

This concept is supposed interesting for us to reconsider fluid power role in industry, too

We convince fluid power engineering plays vital importance on " FUTURE MACHINE " , supported by young students . 